\title{
Hatchery-scale trials using cryopreserved spermatozoa of black-lip pearl oyster, Pinctada margaritifera
}

\author{
Belinda Hui ${ }^{1}$, Vincent Vonau ${ }^{1}$, Jacques Moriceau ${ }^{1}$, Roger Tetumu ${ }^{1}$, Vincent Vanaa ${ }^{1}$, \\ Marina Demoy-Schneider ${ }^{2}$, Marc Suquet $^{3}$ and Gilles Le Moullac ${ }^{1, a}$ \\ 1 Ifremer, Laboratoire Domestication de l'Huître perlière, Centre du Pacifique, BP 7004, 98719 Taravao, Tahiti, Polynésie Française \\ 2 Laboratoire Biodiversité terrestre et marine, UMR CNRS EA4239, Université de la Polynésie Française, BP 6570, 98702 Faa'a, \\ Tahiti, Polynésie Française \\ 3 UMR 100 Physiologie et Ecophysiologie des Mollusques marins, Ifremer, Site expérimentale d'Argenton, 11 Presqu'île du Vivier, \\ 29840 Argenton en Landunvez, France
}

Received 6 February 2011; Accepted 13 April 2011

\begin{abstract}
Cryopreservation is a valuable tool for genetic improvement programs. Several bivalve mollusc species have already been the subject of such programs and the Tahitian black pearl oyster industry is now planning the development of selective breeding for desirable traits in Pinctada margaritifera. The ability to cryopreserve spermatozoa would, therefore, offer significant benefits to the cultured black pearl industry. Spermatozoa were cryopreserved with cryoprotectant agent (CPA) $0.7 \mathrm{M}$ trehalose in $0.8 \mathrm{M} \mathrm{Me}_{2} \mathrm{SO}$ and a two-step freezing process was used: straws were first maintained in nitrogen vapour for 10 minutes, then directly plunged into liquid nitrogen and stored for one week before use. The viability of thawed sperm was $23 \%$ lower than that of fresh sperm. When using thawed sperm, therefore, a higher sperm/egg ratio of 100 000:1 was required to reach 80\% oocyte fertilization, compared with 100:1 for fresh sperm. Nevertheless, this first demonstration of cryopreserved sperm fertility in black pearl oyster confirms the hatchery applicability of the cryopreservation technique defined here. Monitoring for larval viability during the first 23 days of life revealed no significant differences between the progeny produced with cryopreserved sperm and that produced using fresh sperm.
\end{abstract}

Key words: Cryopreservation / Spermatozoa / Fertility / Larval rearing / Pearl oyster / Pinctada margaritifera

\section{Introduction}

Black pearl production in French Polynesia relies almost exclusively on the collection of wild spat of the black-lip pearl oyster, Pinctada margaritifera, making the industry highly dependent on natural resources. Additionally, as recruitment varies greatly in space and time, farmers frequently transfer spat between atolls or even between archipelagos.

In pearl culture, many quality aspects of the pearls themselves are determined by the genetics of the graft donor oysters, making donor oysters the focus of genetic selection (Arnaud-Haond et al. 2007). As a consequence, genetic diversity must be safeguarded for the sustainable development of pearl farming in French Polynesia. Gamete cryopreservation could greatly assist the pearl farming industry, both in preserving black pearl oyster lineages and in selective breeding for desirable traits in the future.

\footnotetext{
a Corresponding author: Gilles.Le.Moullac@ifremer.fr
}

Sperm cryopreservation has been applied to several bivalve molluscs (Bougrier and Rabenomanana 1986; Adams et al. 2004a; Acosta-Salmon et al. 2007; Narita et al. 2007), and is potentially a useful tool for their genetic improvement (Adams et al. 2008). Previous studies have indicated that sperm motility is best maintained when spermatozoa are cryopreserved in $0.45 \mathrm{M}$ trehalose, with dimethyl sulfoxide $\left(\mathrm{Me}_{2} \mathrm{SO}\right)$ in the range 0.64 to $1.53 \mathrm{M}$ (Acosta-Salmón et al. 2007; Lyons et al. 2005). Hui et al. (2009) showed that the best post-thawed sperm motility in $P$ margaritifera spermatozoa was obtained using a CPA composed of trehalose $0.7 \mathrm{M}$ combined with $\mathrm{Me}_{2} \mathrm{SO} 0.8 \mathrm{M}$. Acosta-Salmón et al. (2007) showed that freezing protocols using slow to medium-rapid cooling rates $(2.1-$ $5.2{ }^{\circ} \mathrm{C} \mathrm{min}^{-1}$ ) do not influence post-thaw motility index, and that total motility only decreases significantly when spermatozoa are frozen rapidly by plunging into liquid nitrogen (LN).

The quality of cryopreserved sperm is often defined by post-thaw motility, fertilization rates, or hatching rates 
obtained using thawed sperm. The integrity of the spermatozoon plasma membrane is required to maintain fertilization capacity (Graham et al. 1990; Paniagua-Chávez et al. 2006), but this membrane may be damaged by the freezing-thawing process (Grzyb et al. 2003; Cabrita et al. 2005; Horvat et al. 2008). The evaluation of sperm membrane integrity in marine species is based on the use of the fluorescent dyes using microscopy and flow cytometry analysis (Grzyb et al. 2003; Adams et al. 2003). In eastern oyster (Crassostrea virginica), membrane integrity was correlated with the motility of thawed sperm (Paniagua-Chávez et al. 2006).

Lastly, due to the low proportion of females in reared stocks of black-lip pearl oyster and the asynchrony of its gametogenesis (Pouvreau et al. 2000), the number of female $P$. margaritifera ready to spawn at any one time is low. Ammonia treatment can be used to compensate for this imbalance, as the in vitro test of Wada (1963) confirms that the oocyte maturation process can be obtained artificially by stripping the gonad and treating the oocytes with ammonia, as performed on the Japanese pearl oyster P. fucata (Narita et al. 2008).

Following previous work by Hui et al. (2009) on cryoprotectant composition for P. margaritifera sperm, this study was designed to obtain information on the integrity of thawed sperm compared with fresh using fluorescence microscopy. The fertilization ability of thawed sperm was then evaluated using in vitro fertilization assays. Finally, the fertility of cryopreserved/thawed black-lip pearl oyster sperm was tested using naturally-matured oocytes to confirm the hatchery applicability of the sperm cryopreservation technique developed in the present work and larval viability was followed for the next three weeks.

\section{Materials and methods}

\subsection{Gamete collection}

Pearl oysters (mean height \pm SD: $130 \pm 20 \mathrm{~mm}$ ) were transferred from long-line culture at the Ifremer marine farm in Vairao lagoon (Tahiti, French Polynesia) to the laboratory and conditioned in 30-L tubular tanks ( $\varnothing 150 \mathrm{~mm}$, length $800 \mathrm{~mm}$ ), each housing 5 individuals. Seawater $\left(27^{\circ} \mathrm{C}\right)$ was renewed 4 times per hour. A diet of 10000 algal cell ml ${ }^{-1}$, composed of a 2:1 mix of Isochrysis galbana (T-Iso) and Chaetoceros gracilis cells was supplied continuously. After a two month period, mature pearl oysters were selected according to two criteria: the presence of a visibly filled gonad and a biopsy confirming sex and the presence of mature gametes. Shells were opened with a shell-opener, and the visceral mass isolated. Spermatozoa were then stripped and collected with a Pasteur pipette. Concentrated spermatozoa were collected in microtubes $(1.5 \mathrm{ml})$ and maintained at $4{ }^{\circ} \mathrm{C}$ to minimize any loss of viability. Eggs were examined for maturity, based on egg shape and the presence of a nucleus. Spermatozoa were visually assessed for their motility index as described in Sect. 2.4.

\subsection{Gamete counting}

Sperm concentrations were determined on an aliquot of 1/100 diluted spermatozoa using a Thomas haemocytometer.
Oocyte density was determined by counting three aliquots using an Agasse-Lafont haemocytometer.

\subsection{Cryopreservation process}

According to Hui et al. (2009), the cryoprotectant additive (CPA) mixture was composed of $0.7 \mathrm{M}$ trehalose in $0.8 \mathrm{M}$ $\mathrm{Me}_{2} \mathrm{SO}$. CPA was prepared in distilled water. Only batches of sperm presenting a high motility index were selected for cryopreservation. Following Bougrier and Rabenomana (1986) and Smith et al. (2001), sperm was diluted 1:10 (v/v) in the CPA, then drawn by suction into $500 \mu \mathrm{l}$ semen straws of $13 \mathrm{~cm}$ length (IMV, France) containing $350 \mu \mathrm{l}$ sperm in CPA. Samples remained at room temperature for no more than $10 \mathrm{~min}$ between sperm dilution and the start of cooling. For the cooling, the straws were left in liquid nitrogen (LN) vapour, on a tray $3 \mathrm{~cm}$ above the $\mathrm{LN}$ surface for $10 \mathrm{~min}$ before immersion in LN. For thawing, the straws were immersed in seawater at $27^{\circ} \mathrm{C}$ for $25 \mathrm{~s}$.

\subsection{Viability of cryopreserved sperm}

The viability of cryopreserved spermatozoa was compared with that of freshly collected spermatozoa using the Live/Dead Sperm Viability Kit (L-7011, Molecular Probes). SYBR 14 dye was diluted 1:500 (component A) and propidium iodide 1:10 (component B) in sterile sea water, separately. Five $\mu \mathrm{l}$ of component A were added to $100 \mathrm{ml}$ of sample. After 5-10 min, $5 \mathrm{ml}$ of component $\mathrm{B}$ were added to the same sample. After a further 5-10 min, the results of this staining were observed under a fluorescence microscope (Leica). SYBR 14 dye and propidium iodide can be excited with visible-wavelength light. When bound to DNA, the maximum fluorescence emissions of these dyes are $516 \mathrm{~nm}$ and $617 \mathrm{~nm}$, respectively. Sperm stained with SYBR 14, which emits green fluorescence, were considered intact. The fluorochrome propidium iodide (PI) emits red fluorescence for non-viable cells (Grzyb et al. 2003; Paniagua-Chávez et al. 2006). Sperm were collected from three males, as described above. One part of the sample from each male was tested immediately for viability, making an evaluation in triplicate of about 150 fresh spermatozoa per sample. Another part was cryopreserved in CPA (seven straws for each male) and stored in LN for one week. Four samples of sperm from each straw were then evaluated, resulting in the observation of 1500 thawed spermatozoa per male.

\subsection{Sperm density experiment}

The fertilization capacities of fresh and thawed sperm were compared using oocytes artificially matured with ammonia. The oocytes were collected by gonad stripping one mature female, and were washed by adding filtered seawater. The oocytes were released into seawater containing $2 \mathrm{mM} \mathrm{NH}_{3}$ to induce oocyte maturation $\left(20\right.$ oocytes $\left.\mathrm{ml}^{-1}\right)$, which was then estimated by microscopic examination. Oocytes were used 
for fertilization when more than $80 \%$ had undergone germinal vesicle breakdown. Logarithmic densities of spermatozoa ranging from 2 to 100000 per egg, were obtained by serial dilution using straws containing $75 \times 10^{7}$ spermatozoa, previously frozen in CPA (see Sect. 2.3 Cryopreservation process). Fertilization tests were made in duplicate; on 2000 oocytes in $200 \mathrm{ml}$ seawater for $30 \mathrm{~min}$. Tanks were then filled up to $2 \mathrm{~L}$ and kept at $27^{\circ} \mathrm{C}$. Approximately 100 oocytes were examined microscopically two hours post fertilization to determine the fertilization percentage by counting the proportion of cleaved eggs.

\subsection{Demonstration of hatchery application}

The hatchery applicability of this cryopreservation technique was tested at a production scale. Oocytes were obtained from one female by stripping the gonad at the beginning of oocyte release induced by thermal shock. Eight million mature oocytes were collected and divided into three batches in 10 litres each (about 250 oocytes $\mathrm{ml}^{-1}$ ): one fertilized with fresh sperm, one fertilized using three straws of sperm that had been cryopreserved, and one negative control (unfertilized oocytes). The cryopreserved sperm/oocyte ratio was about 10000 , while the fresh sperm/oocyte ratio was 250 , contact time for fertilization was one hour. The eggs were then rinsed on a $20 \mu \mathrm{m}$ mesh and the fertilization rate was evaluated another hour later in triplicate on approximately 100 eggs as described above. The embryos were then transferred into a $150-\mathrm{L}$ incubator tank at the density of 100 embryos $\mathrm{ml}^{-1}$. Twentyfour hours later, the incubator tank was drained onto a $35 \mu \mathrm{m}$ sieve and D-shaped larvae were concentrated in a $5 \mathrm{~L}$ graduated cylinder. D-shaped larvae were counted $(3 \times 20 \mu \mathrm{l})$ and then reared in a through-flow culture system (Magnesen et al. 2006; Rico-Villa et al. 2008; Sarkis et al. 2006) in 4 replicates. D-shaped larvae were fed using three tropical species of micro-algae: Isochrysis clone T-Iso, Chaetoceros minus and Chaetoceros gracilis. During larval rearing, larvae were sieved at day 13 and day 19 on $60 \mu \mathrm{m}$ and $80 \mu \mathrm{m}$ mesh, respectively, to remove the remains of any dead larvae. Larval counts and measurements of shell height were conducted in triplicate every two days. Larvae were concentrated in a $5 \mathrm{~L}$ graduated cylinder and the number of larvae was assessed in a sample ranging from $20 \mu \mathrm{l}$ to $1 \mathrm{ml}$ in volume. Larval final size at day 23 was assessed in triplicate using digital pictures. Larvae samples were transferred into wells of transparent plates (Greiner Comboplate) and formalin-fixed to be digitalized (4800 dots per inch) using a scanner (Epson). Larval size was assessed by measuring the major axis of an ellipse representing each larva (ImageJ 1.39o).

\subsection{Statistics}

Viability of fresh and thawed spermatozoa was compared using a paired $t$ test after arcsin square-root transformation of the proportion of viable spermatozoa.

The effect of freezing on fertilization ability was evaluated using a two way ANOVA to compare fresh and cryopreserved sperm according to spermatozoa/egg ratio on the arcsin square-root transformed fertilization proportions.
Table 1. Comparison of the viability of fresh and cryopreserved sperm (mean $\pm \mathrm{SD})$.

\begin{tabular}{ccccc}
\hline & Fresh & \multicolumn{2}{c}{ Thawed } \\
\hline & mean & $n$ & mean & $n$ \\
& $(\%)$ & & $(\%)$ & \\
\hline Male 1 & $86.0 \pm 0.9^{*}$ & 3 & $54.3 \pm 4.5$ & 7 \\
Male 2 & $72.4 \pm 1.7^{*}$ & 3 & $56.3 \pm 3.8$ & 7 \\
Male 3 & $79.3 \pm 3.1^{*}$ & 3 & $55 \pm 2.9$ & 7 \\
\hline
\end{tabular}

* indicates a significant difference, $p<0.05$.

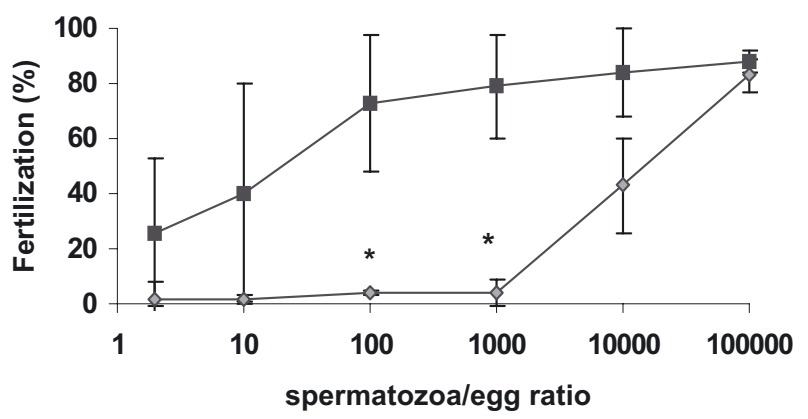

Fig. 1. Effect of sperm density on fertilization rate using fresh (grey) and cryopreserved (black) spermatozoa (mean $\pm \mathrm{SD}, n=3$ males). Oocytes from 1 female were artificially maturated with ammonia (* indicates significantly different means between fresh and cryopreserved spermatozoa at 100 and 1000 spermatozoa/egg ratio).

Survival of larvae from fresh and thawed spermatozoa was compared every two days using a two way ANOVA on the arcsin square-root transformed survival proportion. Larval size at D23 was compared between fresh and thawed spermatozoa using a Student $t$-test.

\section{Results}

\subsection{Viability of cryopreserved spermatozoa}

Viable and non-viable sperm samples displayed both green and red fluorescence. Thawed spermatozoa that had been stored in CPA showed significantly lower viability than fresh spermatozoa (Table 1). The viability of sperm of each male declined significantly $(p<0.05)$ by $31.7,16.1$ and $21.8 \%$ following cryopreservation compared to the viability of fresh spermatozoa from the same males.

\subsection{Fertilization assays}

Comparable fertilization rates of about $80 \%$ were obtained using 100000 thawed spermatozoa per egg and 100 fresh spermatozoa per egg (Fig. 1). Significant differences in fertilization rate between fresh and thawed spermatozoa appeared at 100 and 1000 spermatozoa/egg $(p<0.05)$.

\subsection{Hatchery applicability}

The fertilization rates of oocytes mixed with fresh spermatozoa, spermatozoa cryopreserved with CPA or no 


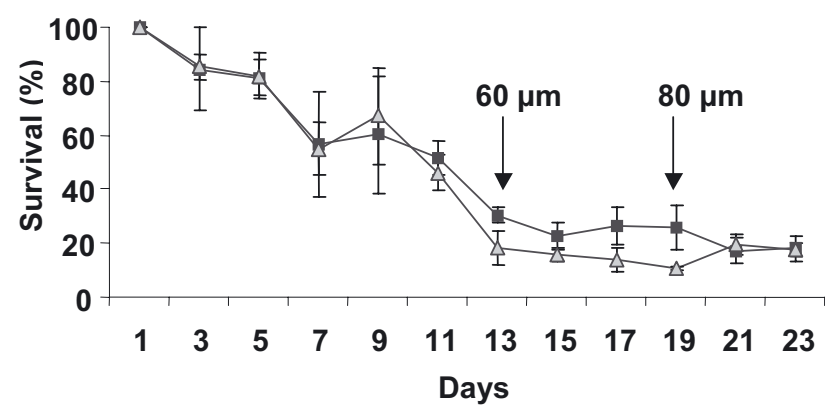

Fig. 2. Comparative survival of larvae obtained using fresh (grey) and cryopreserved (black) spermatozoa. (mean $\pm \mathrm{SD}, n=4)$. Arrows show sievings (mesh size indicated) performed to remove debris from the larval rearing containers.

spermatozoa were $97 \%, 83 \%$ and $0 \%$, respectively. The hatching rates with fresh spermatozoa and cryopreserved spermatozoa were $99 \%$ and $97 \%$ respectively. There was a significant effect of rearing time on larval survival $(F=67.06$, $p<0.0001)$, but no significant effect of sperm cryopreservation on larval survival $(F=2.76, p=0.10)$. At day 23 postfertilization, larval survival was $18 \pm 5 \%$ using thawed sperm and $18 \pm 3 \%$ using fresh sperm (Fig. 2). At D23, eyed-larvae size was not significantly different between larvae obtained using fresh sperm $(175 \pm 22 \mu \mathrm{m})$ and larvae obtained using thawed sperm $(195 \pm 18 \mu \mathrm{m})$.

\section{Discussion}

The present work demonstrated that a good fertilization capacity can be successfully maintained in black-lip pearl oyster sperm through freezing in liquid nitrogen and subsequent thawing. The combination of trehalose $0.7 \mathrm{M}$ and dimethyl sulfoxide $0.8 \mathrm{M}$ allowed sperm integrity and fertilisation ability to be preserved, enabling the production of larvae from cryopreservation sperm.

The assessment of dual stained spermatozoa is a simple and efficient tool for quantifying cell membrane integrity, as previously shown on sperm of other marine invertebrates (Smith et al. 2001) and fish species (Flajshans et al. 2004). Considering other molluscs, the membrane integrity of thawed sperm of eastern oyster (Crassostrea virginica), evaluated using fluorescent dyes, was seen to be correlated with sperm motility (Paniagua-Chavez et al. 2006). The mitochondrial membrane potential of fresh sperm was assessed using rhodamine 123 (Adams et al. 2003, 2004a, 2004b). These other methods should also now be tested on black-lip pearl oyster sperm.

In black-lip pearl oyster, a maximum fertilization rate was observed using 100 fresh sperm per egg. The same ratio was reported in the mangrove oyster (Santos and Nascimento 1989). Higher ratios of 500 and 1000 have been reported in Pacific oyster (Song et al. 2009) and in scallop Pecten fumatus (Heasman et al. 1996), respectively.

The quality of thawed sperm from marine species depends on multiple factors including sperm morphology, metabolism and motility The fertilization capacity of thawed sperm integrates these multiple parameters and can be considered as the ultimate test of sperm quality. Our study is the first time the fertilization capacity of thawed sperm has been reported in this species. We found that, compared with fresh sperm, the sperm to egg ratio required to obtain maximum fertilization rate using thawed sperm needs to be 100 times higher. In Pacific oyster, maximum fertilization rates of thawed sperm were noted for ratios ranging from 1000 to 10000 (Adams et al. 2008). In the Japanese pearl oyster, the decrease in the fertilization capacity of thawed sperm can be compensated by increasing sperm to egg ratio to make it 10 times higher than that used for fresh sperm (Narita et al. 2008). The lower fertilization capacity of black-lip pearl oyster thawed sperm compared with fresh sperm may reflect the $25 \%$ decrease in sperm motility and $23 \%$ decrease in sperm viability.

The fertilization capacity of thawed sperm needs to be tested using discriminating conditions. In seabass (Dicentrarchus labrax), insemination at 35000 spermatozoa per egg was sensitive to variations in sperm quality due to the freezing/thawing process. In contrast, no difference in the fertilization capacity was observed between fresh and thawed sperm using 70000 spermatozoa per egg (Fauvel et al. 1998). The fertilization capacity of thawed black-lip pearl oyster sperm needs to be tested using a discriminating sperm to egg ratio, and our work shows that this ratio is in the range 1000 to 10000 .

The performances of oyster progenies produced using frozen sperm are rarely tested during subsequent rearing steps. In a similar way to observations reported on Crassostrea tulipa (Yankson and Moyse 1991), the survival and size of blacklip pearl oyster larvae during larval rearing were not significantly different when oocytes were inseminated with fresh or thawed spermatozoa. This suggests the absence of genome alterations that might have affected embryonic development. Using a comet assay, alterations were observed in chromatin structure of Pacific oyster spermatozoa after thawing (Gwo et al. 2003). The possible damage to black-lip pearl oyster spermatozoa needs be assessed in future research.

In conclusion, this first demonstration of the fertility of cryopreserved black pearl oyster sperm and subsequent development of larvae confirms that the cryopreservation technique used in this work is applicable at the hatchery scale.

Acknowledgements. This work was supported by the grant RegenPerl 2010-2011 funded by the French government and by the Service de la Perliculture of French Polynesia. Thanks also to Helen McCombieBoudry for improving the English in this paper.

\section{References}

Acosta-Salmón H., Jerry D.J., Southgate P.C., 2007, Effects of cryoprotectant agents and freezing protocol on motility of black-lip pearl oyster (Pinctada margaritifera L.) spermatozoa. Cryobiology 54, 13-18.

Adams S.L., Hessian P.A., Mladenov P.V., 2003, Flow cytometric evaluation of mitochondrial function and membrane integrity of marine invertebrate sperm. Invertebr. Reprod. Dev. 44, 45-51. 
Adams S.L., Hessian P.A., Mladenov P.V., 2004a, Cryopreservation of sea urchin (Evechinus chloroticus) sperm. Cryo Lett. 25, 287300 .

Adams S.L., Smith J.F., Roberts R.D., Janke A.R., Kaspar H.F., Tervit H.R., Pugh P.A., Webb S.C., King N.G., 2004b, Cryopreservation of sperm of the Pacific Oyster (Crassostrea gigas): development of a practical method for commercial spat production. Aquaculture 242, 271-282.

Adams S.L., Smith J.F., Roberts R.D., Janke A.R., King N.G., Tervit H.R., Webb S.C., 2008, Application of sperm cryopreservation in selective breeding of the Pacific oyster, Crassostrea gigas (Thunberg). Aquac. Res. 39, 1434-1442.

Arnaud-Haond S., Goyard E., Vonau V., Herbaut C., Prou J., Saulnier D., 2007, Pearl Formation : Persistence of the Graft During the Entire Process of biomineralization. Mar. Biotechnol. 9, 113116.

Bougrier S., Rabenomanana L.D., 1986, Cryopreservation of spermatozoa of the Japanese Oyster, Crassostrea gigas. Aquaculture 58, 277-280.

Cabrita E., Robles V., Cuñado S., Wallace J.C., Sarasquete C., Herráez, M.P., 2005, Evaluation of gilthead sea bream, Sparus aurata, sperm quality after cryopreservation in $5 \mathrm{ml}$ macrotubes. Cryobiology 50, 273-284.

Fauvel C., Suquet M., Dreanno C., Zonno V., Menu B., 1998, Cryopreservation of sea bass (Dicentrarchus labrax) spermatozoa in experimental and production stimulating conditions. Aquat. Living Resour. 11, 387-394.

Flajshans M., Cosson J., Rodina M., Linhart O., 2004, The application of image cytometry to viability assessment in dual fluorescence-stained fish spermatozoa. Cell Biol. Inter. 28, 955959.

Graham J.K., Kunze E., Hammerstedt R.H., 1990, Analysis of sperm cell viability, acrosomal integrity, and mitochondrial function using flow cytometry. Biol. Reprod. 43, 55-64.

Grzyb K., Rychlowski M., Biegniewska A.,. Skorkowski E.F., 2003, Quantitative determination of creatine kinase release from herring (Clupea harengus) spermatozoa induced by tributyltin. Comp. Biochem. Physiol. C 134, 207-213.

Gwo J.C., Wu C.Y., Chang W.S.P., Cheng H.Y., 2003, Evaluation of damage in Pacific oyster (Crassostrea gigas) spermatozoa before and after cryopreservation using comet assay. Cryo. Lett. 24, $171-180$.

Heasman M.P., O’Connor W.A., Frazer A.W., 1996, Effects of fertilization and incubation factors on the quality and yield of scallop, Pecten fumatus Reeve larvae. Aquac. Res. 27, 505-513.

Horvat A., Wayman W.R., Dean J.C., Urbanyi B., Tiersch T.R., Mims S.D., Johnson D., Jenkins J.A., 2008, Viability and fertilizing capacity of cryopreserved sperm from three North American acipenseriform species: a retrospective study. J. Appl. Ichthyol. 24, 443-449.
Hui B., Demoy-Schneider M., Vonau V., Le Moullac G., Moriceau J., Le Pennec M., Cochard J.C., 2009, Gamete cryopreservation, an asset for a durable pearl farming in French Polynesia. 11th Pacific Science Inter-congress, Tahiti, 2-6 March 2009.

Lyons L., Jerry D.R., Southgate P.C., 2005, Cryopreservation of black-lip pearl oyster (Pinctada margaritifera L.) spermatozoa: effects of cryoprotectants on spermatozoa motility. J. Shellfish Res. 24, 1187-1190.

Magnesen T., Bergh O., Christophersen G., 2006, Yields of great scallop, Pecten maximus, larvae in a commercial flow-through rearing system in Norway. Aquac. Int. 14, 377-394.

Narita T., Kawamoto T., Isowa K., Aoki H., Hayashi M., Komaru A., Ohta H., 2007, Effects of cryopreservation methods on post-thaw motility of spermatozoa from the Japanese pearl oyster, Pinctada fucata martensii. Cryobiology 54, 19-26.

Narita T., Kawamoto T., Isowa K., Aoki H., Hayashi M., Komaru A., Ohta H., 2008, Fertility of cryopreserved spermatozoa of the Japanese pearl oyster, Pinctada fucata martensii. Aquaculture 275, 178-181.

Paniagua-Chávez C.G., Jenkins J., Segovia M., Tiersch T.R., 2006, Assessment of gamete quality for the eastern oyster (Crassostrea virginica) by use of fluorescent dyes. Cryobiology 53, 128-138.

Pouvreau S., Gangnery A., Tiapari J., Lagarde F., Garnier M., Bodoy A., 2000, Gametogenic cycle and reproductive effort of the tropical blacklip pearl oyster, Pinctada margaritifera (Bivalvia: Pteriidae), cultivated in Takapoto atoll (French Polynesia). Aquat. Living Resour. 13, 37-48.

Rico-Villa B., Woerther P., Mingant C., Lepiver D., Pouvreau S., Hamon M., Robert R., 2008, A flow-through rearing system for ecophysiological studies of Pacific oyster Crassostrea gigas larvae. Aquaculture 282, 54-60.

Santos A.E., Nascimento I.A., 1989, Influence of gamete density, salinity and temperature on the normal embryonic development of the mangrove oyster Crassostrea rhizophorae. Aquaculture 73, 295-307.

Sarkis S., Helm M., Hohn C., 2006, Larval rearing of calico scallops, Argopecten gibbus, in a flow-through system. Aquac. Int. 14, 527-538.

Smith J.F., Pugh P.A., Tervit H.R., Roberts R.D., Janke A.R., Kaspar H.F., Adams S.L., 2001, Cryopreservation of shellfish sperm, eggs and embryos. Proc. N. Z. Soc. Anim. Prod. 61, 31-34.

Song Y.P., Suquet M., Quéau I., Lebrun L., 2009, Setting of a procedure for experimental fertilization of Pacific oyster (Crassostrea gigas) oocytes. Aquaculture 287, 311-314.

Wada S.K., 1963, Studies on the fertilization of Pelecypod gamete. Increase in maturity and accomplishment of fertilization of pearl oyster gametes in ammoniacal sea water. Mem. Fac. Fish. Kagoshima Univ. 12, 92-108.

Yankson K., Moyse J., 1991, Cryopreservation of the spermatozoa of Crassostrea tulipa and three other oysters. Aquaculture 97, 259267. 